\title{
Novel Polymeric Thin-Film Composite Membranes for High-Temperature Gas Separations
}

\author{
Fynn Weigelt ${ }^{1,2,+}$, Sara Escorihuela ${ }^{1,2,+}+\mathbb{D}$, Alberto Descalzo ${ }^{1,2}$, Alberto Tena ${ }^{1, *(D)}$, \\ Sonia Escolástico ${ }^{2}{ }^{\circ}$, Sergey Shishatskiy ${ }^{1}{ }^{\mathbb{D}}$, Jose Manuel Serra ${ }^{2, *} \mathbb{C}^{\circ}$ and Torsten Brinkmann ${ }^{1, *}$ \\ 1 Helmholtz-Zentrum Geesthacht, Institute of Polymer Research, Max-Planck-Str.1, 21502 Geesthacht, \\ Germany; fynn.weigelt@hzg.de (F.W.); saesro@itq.upv.es (S.E.); albertodescalzo5@gmail.com (A.D.); \\ sergey.shishatskiy@hzg.de (S.S.) \\ 2 Instituto de Tecnología Química, Universitat Politècnica de València-Consejo Superior de Investigaciones, \\ Científicas, Avda. Los Naranjos, s/n, 46022 Valencia, Spain; soesro@upvnet.upv.es \\ * Correspondence: alberto.tena@hzg.de (A.T.); jmserra@itq.upv.es (J.M.S.); torsten.brinkmann@hzg.de (T.B.) \\ + These authors contributed equally to this work.
}

Received: 13 March 2019; Accepted: 8 April 2019; Published: 10 April 2019

check for updates

\begin{abstract}
Novel selective polymeric thin-film composite membranes (TFCMs) for applications at elevated temperatures were developed. Thin selective layers of the polyimides Matrimid $5218^{\circledR}$ and 6FDA-6FpDA were cast on a developed polybenzimidazole (PBI) porous support prepared by a phase inversion process. The TFCM properties were investigated with different gases in a wide temperature range, including temperatures up to $270{ }^{\circ} \mathrm{C}$. The membranes showed very high thermal stability and performed well at the elevated temperatures. The development of highly thermally resistant polymeric membranes such as these TFCMs opens opportunities for application in high-temperature integrated processes, such as catalytic membrane reactors for the water-gas shift reaction in order to maximize $\mathrm{H}_{2}$ yield.
\end{abstract}

Keywords: thin-film composite membranes; high-temperature applications; high thermal stability; hydrogen; carbon dioxide

\section{Introduction}

Membranes offer attractive opportunities for a great number of gas separation applications, such as air separation, hydrogen purification, or natural gas upgrading [1]. Considering the nature of the membrane selective layer, membranes can be classified as polymeric, metallic, ceramic, and carbonaceous [1-3]. Materials are selected according to the application conditions and requirements. Although polymeric membranes exhibit clear benefits in terms of processability and relatively low price, they also have some drawbacks, such as low thermal and chemical stability, that have to be carefully considered with respect to the selected application [4].

In order to apply the selective materials in an industrial process, the polymeric membranes must be processed as a thin selective layer $(<100 \mathrm{~nm})$. Since the layer is very thin, the materials must be supported [5-7]. One method to obtain a supported selective layer is by the formation of thin-film composite membranes (TFCMs). In this case, the supporting structures should possess good mechanical properties and, together with the selective layer, should have high thermal and chemical stability, whilst simultaneously being highly permeable. Obviously, a thinner selective layer leads to higher flux through the membrane. The multilayer concept of TFCMs is very attractive in terms of simplicity and cost compared to integral asymmetric membranes, where the material of the selective layer needs to be the same as the material of the porous support. This fact opens the way for practical use of expensive tailor-made polymers and other materials which are often too expensive or not 
stable enough to be used for the formation of the whole membrane structure [8]. There are multiple materials with promising properties for specific applications but with applicability limitations such as in cost, upscaling, stability, or mechanical or other physical-chemical properties. These problems can be solved by using inexpensive materials as porous support, and by placing a very thin layer of the selective-and more expensive-material on top [6,7]. In this way, we can match the selective layer and the support material for a specific application.

Typical polymeric supporting materials are made from commercial materials such as polyacrylonitrile or polyetherimide $[6,9,10]$. These porous support materials are not stable at elevated temperatures (greater than $180-200{ }^{\circ} \mathrm{C}$ ). This issue can be solved by using more thermally stable supports, such as ceramics. The main limitation of this approach is the compatibility between ceramic support and the polymeric layer. This problem was solved by studying the limitations of the coating process [11]. Despite the high thermal and chemical stability, the use of ceramic supports presents some limitations [12], especially in terms of compatibility with the polymeric layer. In terms of the selective layer, glassy polyimides present excellent separation properties as well as very good thermal and chemical stability [13-16]. Therefore, the ideal situation can be found when both support and selective layer are polymeric materials.

In polymeric gas separation membranes, the mass transfer is described according to the solution-diffusion mechanism [1]. In the solution-diffusion theory of molecular transport in polymers, the permeability $\left(P_{i}\right)$ coefficient is determined by two factors (Equation (1)): The solubility, $S_{i}$, related to the properties of the gas and to its interaction with the polymer matrix. It reflects the number of molecules dissolved in the membrane material. Since it depends on molecular interaction, it is an equilibrium term. On the other hand, the diffusivity, $D_{i}$, depends mainly on the ability of the gas molecules to move through the bulk of a polymer by migrating from one free volume void to another.

$$
P_{i}=D_{i} \cdot S_{i}
$$

At elevated temperatures, as in the case of several industrial processes, the solubility factor becomes less important compared to the more dominant diffusivity factor compared to ambient temperatures. Therefore, under the here-described conditions, the major influence of the permeability selectivity (Equation (2)) is mostly seen in the differences in the diffusion coefficients of gases dissolved in the polymer. An additional explanation employs the temperature dependencies of the two coefficients. The heat of sorption $\Delta H_{S}$ consists of the heat of mixing and the heat of condensation, and can be either positive or negative [17]. The activation energy of diffusion $E_{d}$ is always positive, and for permanent gases its absolute value always is considerably larger than the absolute value of the heat of sorption [18].

$$
\alpha_{i j}=\alpha_{D} \cdot \alpha_{S}=\left[\frac{D_{i}}{D_{j}}\right] \cdot\left[\frac{S_{i}}{S_{j}}\right]
$$

Especially for polymers, this consideration limits the choice of selective materials to glassy polymers, where permeability selectivity is directed by the diffusion selectivity, and not by the solubility selectivity. The largest use of syngas is hydrogen production, where steam methane reforming (SMR) is the predominant technology. The latter is a well-established process with two main reactions: reforming and water-gas shift (WGS) reactions $[12,19,20]$.

The endothermic methane steam reforming reaction is:

$$
\mathrm{CH}_{4}+\mathrm{H}_{2} \mathrm{O} \rightleftharpoons \mathrm{CO}+3 \mathrm{H}_{2} \quad \Delta H=+206.2 \frac{\mathrm{kJ}}{\mathrm{mol}} .
$$

Afterwards, the carbon monoxide reacts further with steam to form $\mathrm{H}_{2}$ and $\mathrm{CO}_{2}$, by the weakly exothermic water-gas shift reaction:

$$
\mathrm{CO}+\mathrm{H}_{2} \mathrm{O} \rightleftharpoons \mathrm{CO}_{2}+\mathrm{H}_{2} \quad \Delta H=-41.2 \frac{\mathrm{kJ}}{\mathrm{mol}}
$$


In order to use this hydrogen, a purification step of the mixture $\mathrm{CO}, \mathrm{CO}_{2}$, and $\mathrm{H}_{2}$ is necessary. The composition of the mixture varies depending on the source and the intended use of the synthesis gas. A typical example is ammonia synthesis, where the gas exiting the low-temperature water-gas shift reaction contains $44 \%$ hydrogen, $13 \% \mathrm{CO}_{2}$, and $28 \%$ water, among other gases [21]. Low-temperature WGS reactors using $\mathrm{Cu}$-Zn catalyst systems are operated at about $200{ }^{\circ} \mathrm{C}$ [21]. For high-temperature WGS reactors employing Fe-CR catalysts, membranes that can withstand temperatures above $300{ }^{\circ} \mathrm{C}$ and upstream pressures of up to $2.7 \mathrm{MPa}$ are needed [22].

In the literature there are only a few works available discussing high-temperature measurements of polymeric gas separation membranes. Most of them are about hollow fiber polybenzimidazole (PBI) membranes [23-25]. Costello and Koros describe dense films of 6FDA-6FpDA and 6FDA-6FmDA membranes at elevated temperatures up to $300{ }^{\circ} \mathrm{C}$ [26].

To expand the applicability of polymeric materials to these types of high-temperature processes, it is necessary to provide new thermally and chemically stable porous support structures to produce TFCMs. Therefore, in this work, a highly thermally resistant polymeric porous support is developed and combined with dense layers of thermally stable polymers. The characterization was performed taking into account the later application for hydrogen separation. Efforts were carried out to improve the membrane stability, enabling its operation temperature up to $270{ }^{\circ} \mathrm{C}$. This is a temperature range which is interesting for separation processes in the petrochemical industry and for use in catalytic membrane reactors.

\section{Experimental}

\subsection{Materials}

\subsubsection{Non-Woven Support}

The non-woven polyphenylene sulfide (PPS) has a high porosity as well as excellent thermal and chemical stabilities. The supplier cannot be disclosed due to license issues.

\subsubsection{Polymers}

Polybenzimidazole (PBI), a poly[2,2'-(m-phenylene)-5,5'-bibenimidazole], was purchased from $\mathrm{PBI}^{\circledR}$ Performance products, Inc. (Charlotte, NC, USA) in a $26 \mathrm{wt}$. \% solution. Polyethylene glycol (PEG) with an average molecular weight of $2000 \mathrm{~g} \mathrm{~mol}^{-1}$ was obtained from Sigma-Aldrich (St. Louis, MO, USA). The polyimide Matrimid ${ }^{\circledR} 5218$ (Matrimid ${ }^{\circledR}$ ) was purchased from Huntsman Advanced Materials GmbH (Berkamen, Germany) in powder form. The polyimide 6FDA-6FpDA was synthesized for the current work according to procedure described elsewhere [27]. Teflon ${ }^{\circledR}$ AF 2400 was purchased from E. I. du Pont de Nemours (Wilmington, DE, USA).

\subsubsection{Solvents}

Tetrahydrofuran (THF), dimethyl acetamide (DMAc), and toluene were purchased from Merck $\mathrm{GmbH}$ (Darmstadt, Germany). 3M ${ }^{\mathrm{TM}}$ Fluorinert $^{\mathrm{TM}}$ FC-770, $>99 \%$, was purchased from IOLITEC Ionic Liquids Technologies GmbH (Heilbronn, Germany). All solvents were used as received.

\subsubsection{Gases}

Gases were purchased from Linde AG and had purities of at least $99.99 \%$.

\subsection{Membranes}

\subsubsection{Thick Films}

Dense homogeneous films of Matrimid ${ }^{\circledR}$, 6FDA-6FpDA, and Teflon ${ }^{\circledR}$ AF 2400 were prepared by casting the polymer solution (in THF and FC-770 for Teflon ${ }^{\circledR}$ AF 2400) on a leveled glass plate and 
drying under constant dry nitrogen flow. When the solvent evaporation was complete, the membranes were dried for $6 \mathrm{~h}$ at $200{ }^{\circ} \mathrm{C}$ under vacuum. The thickness of the homogenous membranes was determined using a Fischer Deltascope FMP10 (Helmut Fischer GmbH, Sindelfingen, Germany). The thickness of the Matrimid ${ }^{\circledR}$ dense film was $30.1 \pm 0.1 \mu \mathrm{m}$, the thickness of the 6FDA-6FpDA was $16.8 \pm 0.1 \mu \mathrm{m}$, and the thickness of the Teflon ${ }^{\circledR}$ AF 2400 was $25.4 \pm 0.1 \mu \mathrm{m}$.

\subsubsection{Preparation of TFCMs}

The porous support for the TFCMs (Figure 1) were prepared on a non-woven PPS support on a lab-scale membrane casting machine [28]. First the purchased PBI solution was diluted with DMAc to the concentration of $18 \mathrm{wt}$. \% of PBI. As a porosity modifier, $6 \mathrm{wt}$. \% PEG 2000 was added to the solution. On the lab-scale casting machine, the PBI solution was cast on the non-woven PPS and the porous PBI support was obtained by phase inversion [29]. Water was used as a non-solvent of the coagulation bath at a temperature of $20{ }^{\circ} \mathrm{C}$. After the casting, the porous support was extensively washed with an excess of hot water and dried afterwards.

I.

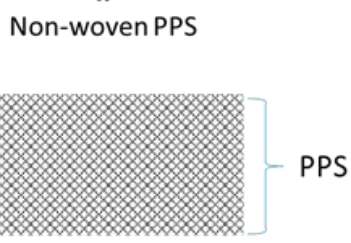

IV.

$2 \times$ dip coating

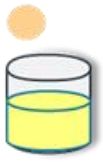

II.

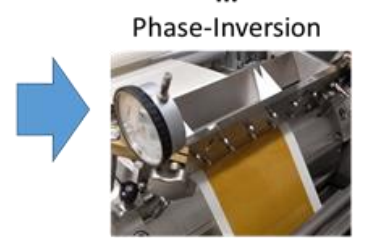

V.

Thin film composite Teflon AF2400

membrane

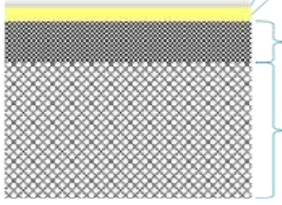

III.

Porous $\mathrm{PBI}$

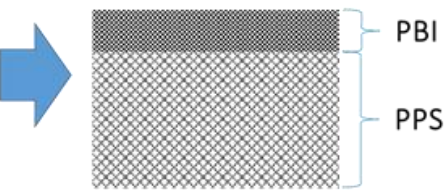

Selective layer

$\mathrm{PBI}$

PPS

Figure 1. Sketch of the production steps to form thin-film composite membranes (TFCMs) with four layers: polyphenylene sulfide (PPS) as a non-woven support, polybenzimidazole (PBI) as a porous support, Matrimid ${ }^{\circledR}$ or 6 FDA-6FpDA as a selective layer, and Teflon ${ }^{\circledR}$ AF 2400 as a protective layer.

TFCMs were coated by a dip-coating process. The porous support was first dipped in toluene in order to fill the pores. Subsequently, the samples were dip coated with the polymer solution (4 wt. \% Matrimid ${ }^{\circledR}$ or $3.5 \mathrm{wt}$. \% 6FDA-6FpDA) and subsequently dried at $50{ }^{\circ} \mathrm{C}$ for $24 \mathrm{~h}$. Afterwards, the samples were dip coated in a solution of $1 \mathrm{wt}$. \% Teflon ${ }^{\circledR}$ AF2400 in FC 770 to get a protective layer. Time of dip coating was controlled to $10 \mathrm{~s}$. The TFCMs were dried in an oven under vacuum for $24 \mathrm{~h}$ at $260{ }^{\circ} \mathrm{C}$ to ensure that all the solvent used during the process was evaporated [30].

\subsection{Characterization Methods}

The "time-lag" and the "pressure increase" (variable pressure, constant volume [31]) methods for thick dense films and for TFCMs, respectively, were used to determine the gas transport parameters. The temperature ranged from 30 to $70{ }^{\circ} \mathrm{C}$ and a $100 \mathrm{mbar}$ feed pressure was used for $\mathrm{H}_{2}, \mathrm{~N}_{2}, \mathrm{O}_{2}$, $\mathrm{CO}_{2}$, and $\mathrm{CH}_{4}$. The first method relied on maintaining a constant feed pressure while monitoring the permeate pressure, which changed as a function of time due to the transport of gas molecules through the membrane. The measurement of the increase in pressure in the permeate chamber of known constant volume started at the time point when the gas at the constant pressure was brought in contact with the membrane. The time-lag, $\theta$, was determined by extrapolating the slope of the linear increase to its intersection with the time axis. Additionally, the gas permeability coefficient of the membrane was calculated from the linear part of the curve. The permeability $\left(P_{\text {eff }, i}\right)$ of a gas 
penetrant $i$ is the pressure or fugacity difference (i.e., driving force) and thickness-normalized flux of the component through the membrane and is defined by:

$$
P_{e f f, i}=\frac{N_{i} l}{A_{m} \Delta p_{i}}
$$

where $P_{\text {eff }, i}$ is the permeability of component $i, N_{i}$ is the volumetric flowrate of the component $i$ at standard conditions (STP) through the membrane, $A_{m}$ is the membrane area, and $\Delta p_{i}$ the partial pressure (or fugacity) difference between feed and permeate sides. The single gas permeance $L_{e f f, i}$ can be calculated by:

$$
L_{e f f, i}=\frac{P_{e f f, i}}{l}=\frac{N_{i}}{A_{m} \Delta p_{i}} .
$$

The volumetric flowrate was determined from the permeate pressure change with time assuming that the ideal gas law is applicable in the pressure range of $0-10$ mbar (i.e., the working range of the permeate-side pressure sensor). The ideal selectivity $\alpha$ of a dense gas separation membrane is defined as:

$$
\alpha_{i, j}=\frac{P_{i}}{P_{j}}=\frac{L_{i}}{L_{j}}
$$

where $P_{i}$ and $P_{j}$ are the permeabilities of gases $i$ and $j$.

A custom-built machine was used for the "time-lag" and "pressure-increase" measurements. The machine employs two software based evaluation modes: one designed for experiments involving thick isotropic films and allowing for determination of the diffusion, solubility, and permeability coefficients of gases; and the second designed for the determination of the gas transport properties of practical membranes having selective layers thin enough to neglect the time lag caused by the diffusion of gas molecules through the bulk of the selective layer material.

Single gas measurements at high temperature were performed in a module designed for this purpose. The set-up (Figure 2) consisted of: (a) three mass flow controllers (MF_1-MF_3) for $\mathrm{H}_{2}$ and $\mathrm{CO}_{2}$ as feed gases and $\mathrm{Ar}$ as sweep gas; (b) two manometers to control the internal pressure in both chambers of the reactor (feed side and permeate side); (c) a micro GC to measure the outlet gases at the permeate side; and finally (d) a reactor with two chambers that allow the membrane to be placed and sample to be sealed by rubber rings in the center. Membranes were placed in the center of the reactor and sealed from both sides. Hence, two well-defined chambers separated by the membrane sample allowed us to perform measurements at different temperatures.

Fluxes $\left(J_{i}\right)$, in $\mathrm{mLSTP}_{\mathrm{ST}} \mathrm{m}^{-2} \mathrm{~s}^{-1}$, of $\mathrm{H}_{2}$ and $\mathrm{CO}_{2}$ permeating through the membrane were calculated by dividing the gas concentration by the effective surface area of the membranes $A_{m}$, as shown in the following equation:

$$
J_{i}=\frac{\% \cdot Q_{\text {sweep }}}{A_{m}} .
$$

Afterwards, flux was divided by the gas partial pressure difference $\left(\Delta p_{i}\right)$ between the two chambers, and the permeance of the specific gas could be obtained. In order to compare the permeances, the units were converted to $\mathrm{m}_{\mathrm{STP}} \mathrm{m}^{-2} \mathrm{~h}^{-1} \mathrm{bar}^{-1}$.

$$
P_{i}=\frac{J_{i}}{\Delta p_{i}}
$$

Differential scanning calorimetry (DSC) experiments were carried out using the calorimeter DSC 1 (Mettler-Toledo, Gießen, Germany) with the following parameters: nitrogen atmosphere, heating rate $10 \mathrm{~K} / \mathrm{min}$, temperature range from room temperature to $380^{\circ} \mathrm{C}$. Three heating-cooling cycles were conducted with a five-minute isotherm interval between the heating and the cooling, whereas the first heating interval served to erase the sample history from the sample preparation (start temperature: RT, maximal temperature: $180^{\circ} \mathrm{C}$ ), while the other two cycles were applied for the determination of thermal properties. The latter cycles were accomplished in the temperature range $200-380^{\circ} \mathrm{C}$. In this setting, 
the second heating interval was used for the evaluation of the glass transition and the third heating interval was used as verification. The glass transition temperature $T_{g}$ was considered as the inflection point of the heat flow as a function of the temperature with the onset method using the instrumentation software. The midpoints were also estimated using this software. For the measurement, approximately $10 \mathrm{mg}$ of the vacuum dried polymer and the ground composites were placed in an aluminum pan of $10 \mu \mathrm{L}$.

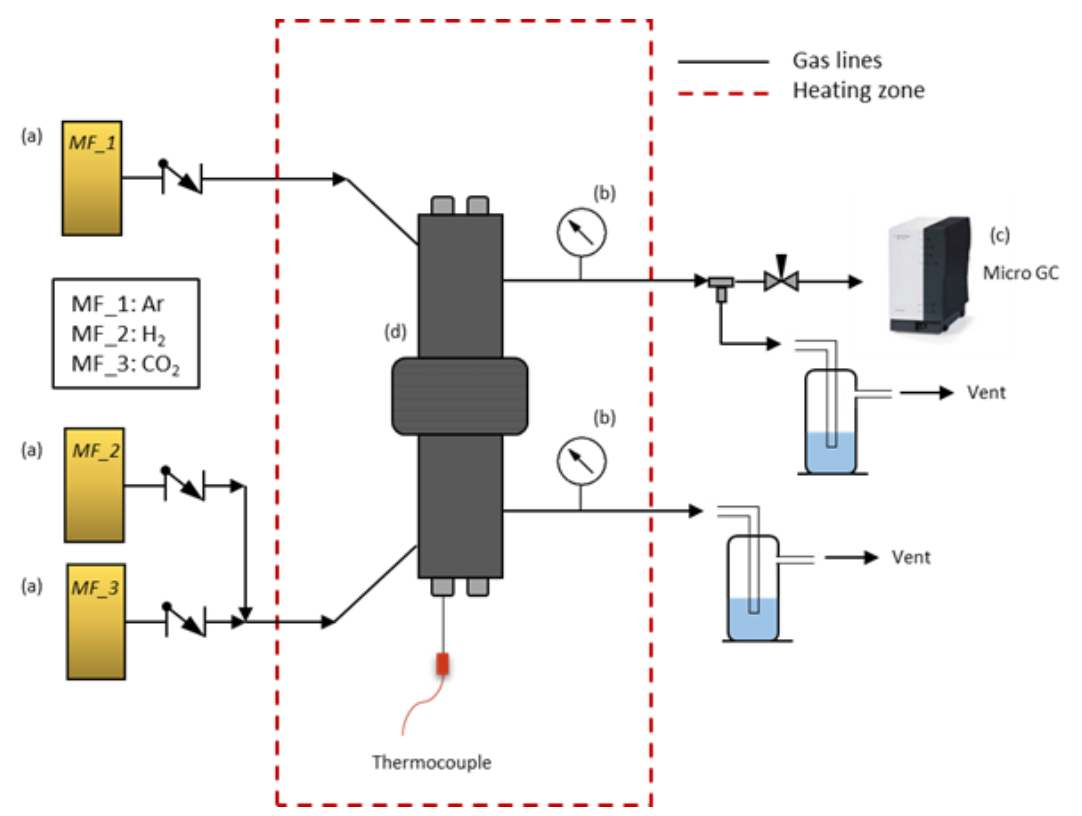

Figure 2. High-temperature set-up for polymeric membranes.

Thermogravimetric analysis (TGA) was carried out using a TG 209 F1 Iris (Netzsch, Selb, Germany). The experimental setup was as follows: temperature range $30-800{ }^{\circ} \mathrm{C}$, heating rate $10 \mathrm{~K} / \mathrm{min}$, nitrogen atmosphere.

The morphology of the membranes was determined by scanning electron microscope (Merlin and Auriga; Carl Zeiss GmbH, Oberkochen, Germany). For this analysis the samples were either cryo-fractured in liquid nitrogen or cut with a focused gallium ion beam (FIB). Afterwards, the samples were sputter-coated with carbon.

\section{Results and Discussion}

The glass transition temperature $\left(T_{g}\right)$ was determined by DSC. The $T_{g}$ of Matrimid ${ }^{\circledR}$ is $320^{\circ} \mathrm{C}$ and the $T_{g}$ of 6 FDA-6FpDA is $310^{\circ} \mathrm{C}$, as reported in previous works [11,32]. The $T_{g}$ of the PBI was $427^{\circ} \mathrm{C}$. These values clearly indicate the applicability of the chosen materials for application in the desired temperature range above $200{ }^{\circ} \mathrm{C}$.

From the TGA curves in Figure 3, it is observed that the different polymeric materials showed high thermal stability. The decomposition started above $300{ }^{\circ} \mathrm{C}$ for each polymer.

The cross-sectional morphology of the porous PBI and the prepared TFCMs was analyzed. The cross section of the porous support is presented in Figures 4 and 5. In the lower part of Figure 4 the non-woven PPS fibers and the porous PBI layer on top can be seen. The porous PBI layer had a thickness of approximately $1 \approx 30 \mu \mathrm{m}$, average pore size of about $100 \mathrm{~nm}$, and a surface porosity of approximately $21 \%$. The nitrogen permeance of the porous PBI was $459 \mathrm{mSTP}^{3} \mathrm{~m}^{-2} \mathrm{~h}^{-1} \mathrm{bar}^{-1}$, and the permeances of the other gases were in agreement with Knudsen-type gas flow through porous media. 


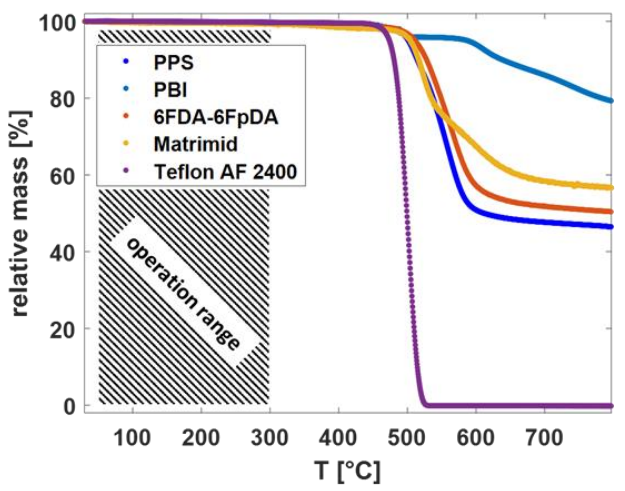

Figure 3. TGA thermographs for the different polymeric materials in dry Ar.
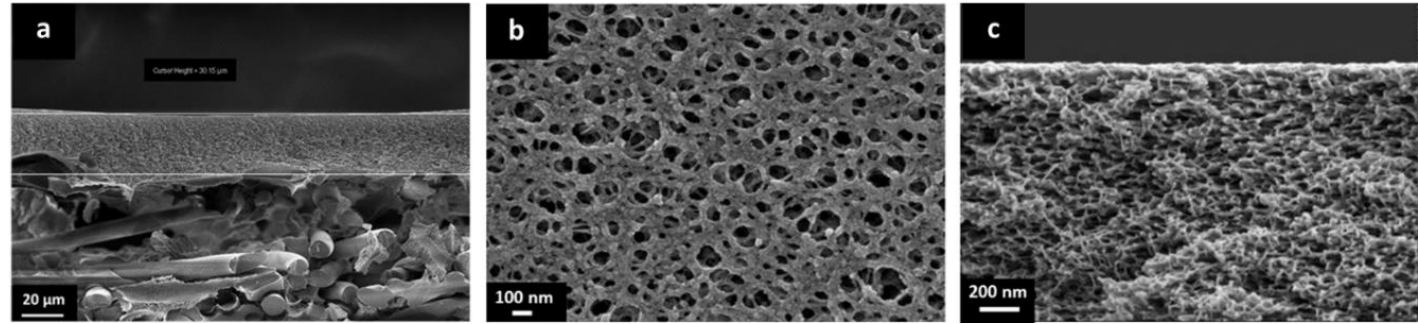

Figure 4. (a) SEM cross section of the support of non-woven PPS and porous PBI structure; (b) SEM surface of the porous PBI structure; and (c) SEM cross section of the porous PBI structure.
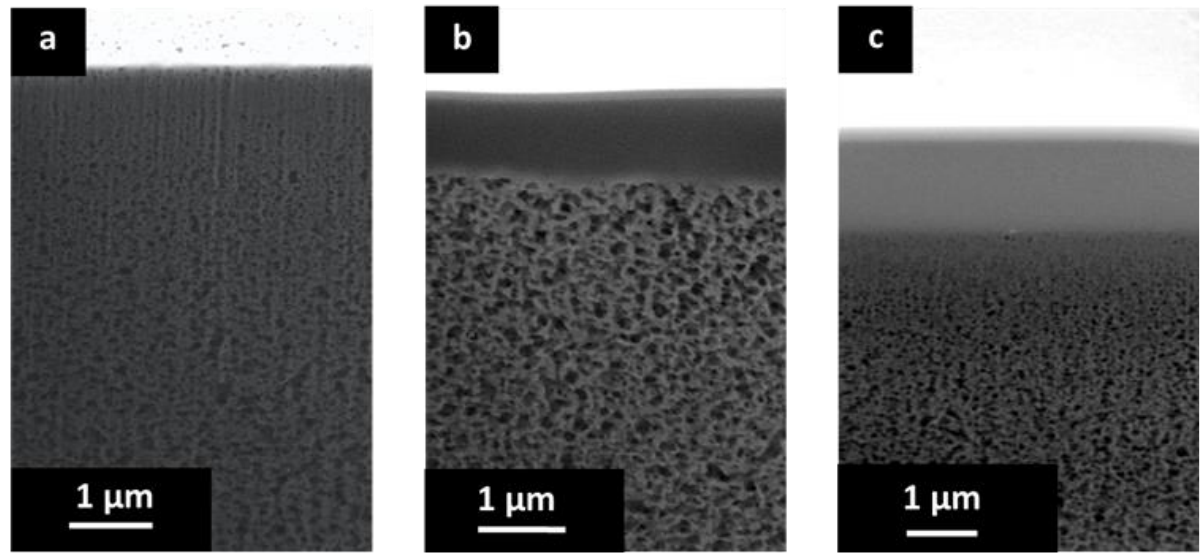

Figure 5. (a) SEM cross section of porous PBI structure; (b) SEM cross-section of the TFCM with a selective layer of Matrimid ${ }^{\circledR}$ and Teflon ${ }^{\circledR}$ AF 2400 protective layer; and (c) SEM cross section of the TFCM with a selective layer of 6FDA-6FpDA and Teflon ${ }^{\circledR}$ AF 2400 protective layer.

Figure 5a shows a higher magnification for the cross section of the porous PBI. In this case, the sample was cut by FIB. The anisotropic nature of the porous PBI structure can be clearly seen, as can pores on the membrane surface.

Figure $5 \mathrm{~b}$ shows the cross-sectional morphology for the TFCM with a Matrimid ${ }^{\circledR}$ selective layer. The Matrimid ${ }^{\circledR}$ layer showed a thickness of about $1 \mu \mathrm{m}$ while the thickness of the Teflon ${ }^{\circledR}$ AF 2400 protective layer was estimated to be under $80 \mathrm{~nm}$. The selective layer and the protective layers were homogenous, without visible defects. No penetration of the Matrimid ${ }^{\circledR}$ into the pores was observed. Figure 4c shows the cross-sectional morphology of the TFCM with 6FDA-6FpDA as the selective layer. According to Figure $5 c$, the selective layer of 6 FDA-6FpDA had a thickness of about $1 \mu \mathrm{m}$ and the protective layer on top of Teflon ${ }^{\circledR}$ AF 2400 was estimated to have a thickness of $100 \mathrm{~nm}$. Figure 5c shows evidence of 6FDA-6FpDA penetration into the pores of the PBI substrate, which was filled with toluene to prevent polymer penetration during the membrane preparation. In this case, the 
polyimide could withstand the presence of toluene in the polymer/THF solution without going into phase inversion. Therefore, the presence of toluene in the PBI structure resulted not just in partial polyimide penetration into the pores but also in toluene penetration into the coating solution as well, causing partial phase inversion in the coating polymer solution during the selective layer drying. This could explain the difference in gas transport results for the TFCM and isotropic 6FDA-6FpDA film discussed below, as well as the differences in the selective layer thickness estimated from SEM images and from gas transport measurements. This was not the case for the Matrimid ${ }^{\circledR}$, where toluene did not allow the polymer to penetrate into the PBI porous structure and, therefore, the selective layer thickness estimated from SEM and gas transport analysis were in good agreement.

The time-lag method was used for the evaluation of the permeability coefficients of the Matrimid ${ }^{\circledR}$ and 6FDA-6FpDA thick films for $\mathrm{H}_{2}, \mathrm{CO}_{2}, \mathrm{O}_{2}, \mathrm{CH}_{4}$, and $\mathrm{N}_{2}$ in the temperature range $30-70{ }^{\circ} \mathrm{C}$, at 1000 mbar feed pressure (Table 1). The ideal gas perm-selectivities at $30{ }^{\circ} \mathrm{C}$ were $\alpha_{\mathrm{H} 2 / \mathrm{CO} 2}=2.6$, $\alpha_{\mathrm{O} 2 / \mathrm{N} 2}=6.2$, and $\alpha_{\mathrm{CO} 2 / \mathrm{CH} 4}=35.7$ for Matrimid ${ }^{\circledR}$ and $\alpha_{\mathrm{H} 2 / \mathrm{CO} 2}=1.4, \alpha_{\mathrm{O} 2 / \mathrm{N} 2}=5.4$, and $\alpha_{\mathrm{CO} 2 / \mathrm{CH} 4}=47.6$ for 6FDA-6FpDA. The activation energy $\left(E_{A, i}\right)$ of permeability was calculated from data obtained in the range $30-70{ }^{\circ} \mathrm{C}$ and is defined from the Arrhenius equation as:

$$
P_{i}(T)=P_{0, i} \cdot e^{\frac{-E_{A, i}}{R \cdot T}}
$$

where $P_{i}$ is the permeability, $P_{0, i}$ is the pre-exponential factor, $R$ is the universal gas constant, and $T$ is the temperature.

Table 1. Separation properties for the thick films at $30^{\circ} \mathrm{C}$ and the activation energy calculated in the temperature range $30-70{ }^{\circ} \mathrm{C}$.

\begin{tabular}{|c|c|c|c|c|c|c|c|c|}
\hline \multirow{2}{*}{ Polymer } & \multirow{2}{*}{ Parameter } & \multicolumn{5}{|c|}{ Gases } & \multicolumn{2}{|c|}{ Selectivity (-) } \\
\hline & & $\mathrm{H}_{2}$ & $\mathrm{CO}_{2}$ & $\mathrm{O}_{2}$ & $\mathrm{CH}_{4}$ & $\mathbf{N}_{2}$ & $\mathrm{O}_{2} / \mathrm{N}_{2}$ & $\mathrm{CO}_{2} / \mathrm{CH}_{4}$ \\
\hline \multirow{2}{*}{ Matrimid $^{\circledR}$} & Permeability (Barrer) * & 18.9 & 7.14 & 1.62 & 0.20 & 0.26 & 6.2 & 35.7 \\
\hline & $E_{A}\left(\mathrm{~kJ} \mathrm{~mol}^{-1}\right)$ & 13.0 & 8.15 & 8.93 & 18.0 & 22.6 & - & - \\
\hline \multirow{2}{*}{ 6FDA-6FpDA } & Permeability (Barrer) * & 74.3 & 53.4 & 10.3 & 1.12 & 1.89 & 5.4 & 47.6 \\
\hline & $E_{A}\left(\mathrm{~kJ} \mathrm{~mol}^{-1}\right)$ & 3.67 & 0.57 & 3.31 & 7.02 & 6.43 & - & - \\
\hline \multirow{2}{*}{$\begin{array}{c}\text { Teflon }{ }^{\circledR} \text { AF } \\
2400\end{array}$} & Permeability (Barrer) * & 1180 & 1248 & 504 & 155 & 222 & 2.3 & 8.1 \\
\hline & $E_{A}\left(\mathrm{~kJ} \mathrm{~mol}^{-1}\right)$ & 5.14 & -3.01 & 3.40 & 9.12 & 7.38 & - & - \\
\hline
\end{tabular}

The pressure increase method was used for the $\mathrm{H}_{2}, \mathrm{CO}_{2}, \mathrm{O}_{2}, \mathrm{CH}_{4}$, and $\mathrm{N}_{2}$ permeance evaluation of the TFCMs with selective layers of Matrimid ${ }^{\circledR}$ and 6FDA-6FpDA and the Teflon AF 2400 protective layer. As in the case of the thick films, the pure gas permeance data was acquired for the TFCMs in the temperature range $30-70{ }^{\circ} \mathrm{C}$ and the data for $30^{\circ} \mathrm{C}$ are presented in Table 2 . The selectivities in the case of the Matrimid ${ }^{\circledR}$ membrane were $\alpha_{\mathrm{H} 2 / \mathrm{CO} 2}=2.2, \alpha_{\mathrm{O} 2 / \mathrm{N} 2}=6.4$, and $\alpha_{\mathrm{CO} 2 / \mathrm{CH} 4}=35.2$; for $6 \mathrm{FDA}-6 \mathrm{FpDA}$ they were $\alpha_{\mathrm{H} 2 / \mathrm{CO} 2}=1.1, \alpha_{\mathrm{O} 2 / \mathrm{N} 2}=4.1$, and $\alpha_{\mathrm{CO} 2 / \mathrm{CH} 4}=33.6$ at $30^{\circ} \mathrm{C}$. The Matrimid ${ }^{\circledR} \mathrm{TFCMs} \mathrm{selectivities}$ agree with the selectivities of the thick film membranes, whilst for the 6FDA-6FpDA TFCMs the selectivities were lower than the ideal selectivities calculated from permeability coefficients. The same trend was observed in the activation energies of the 6FDA-6FpDA membranes. The $E_{A}$ values of the Matrimid ${ }^{\circledR}$ TFCMs were in good agreement with the $E_{A}$ values of the thick-film membranes. For 6FDA-6FpDA, a decrease of the activation energies in the TFCMs was observed. A possible explanation could be the influence of the Teflon ${ }^{\circledR}$ AF 2400 protective layer on overall membrane performance. Table 1 displays the permeabilities and $E_{A}$ values of the Teflon AF 2400. Teflon AF 2400 had high permeabilities and low selectivities. The selectivities for Teflon ${ }^{\circledR}$ AF 2400 were $\alpha_{\mathrm{H} 2 / \mathrm{CO} 2}=1.0$, $\alpha_{\mathrm{O} 2 / \mathrm{N} 2}=2.3$, and $\alpha_{\mathrm{CO} 2 / \mathrm{CH} 4}=8.1$ at $30{ }^{\circ} \mathrm{C}$. In Table 2 , the estimated selective layer thicknesses are presented, as calculated from the gas transport data obtained for isotropic polymer films and TFCMs (i.e., by dividing the permeability by the permeance). For Matrimid ${ }^{\circledR}$ TFCM the calculated selective 
layer thickness was in agreement with the estimated thickness from the SEM image (Figure 5). For 6FDA-6FpDA the calculated selective layer thickness was lower than the estimated layer thickness from the SEM image (Figure 5c). This could explain the difference in the $E_{A}$ values for the TFCM of 6FDA-6FpDA, which may have originated from the observed penetration and partial phase inversion of the 6FDA-6FpDA in Figure 5c. Therefore, the protective Teflon ${ }^{\circledR}$ AF 2400 layer appeared to have a significant influence on the permeance of the 6FDA-6FpDA TFCM. The Teflon ${ }^{\circledR}$ AF 2400 was selected based on its high permissibility to the transport of the gases and due to its high thermal stability. From this, it can be inferred that a much thinner layer of the protective fluorinated polymer should be applied for a fast polymer such as 6FDA-6FpDA.

Table 2. Separation properties for the thin-film composite membranes at $30{ }^{\circ} \mathrm{C}$ and the activation energy calculated in the temperature range from 30 to $70^{\circ} \mathrm{C}$.

\begin{tabular}{|c|c|c|c|c|c|c|}
\hline \multirow{2}{*}{ Polymer } & \multirow{2}{*}{ Parameter } & \multicolumn{5}{|c|}{ Gases } \\
\hline & & $\mathbf{H}_{2}$ & $\mathrm{CO}_{2}$ & $\mathrm{O}_{2}$ & $\mathrm{CH}_{4}$ & $\mathbf{N}_{2}$ \\
\hline \multirow{3}{*}{ Matrimid ${ }^{\circledR}$} & Permeance, $10^{2}\left(\mathrm{~m}_{\mathrm{STP}}^{3} \mathrm{~m}^{2} \mathrm{~h}^{-1} \mathrm{bar}^{-1}\right)^{*}$ & 4.57 & 2.11 & 0.51 & 0.06 & 0.08 \\
\hline & Activation Energy $\left(E_{A}\right)\left(\mathrm{kJ} \mathrm{mol}^{-1}\right)$ & 12.3 & 6.24 & 7.13 & 20.0 & 14.6 \\
\hline & Selective layer thickness ** $(\mathrm{nm})$ & 1120 & 930 & 870 & 1280 & 1330 \\
\hline \multirow{3}{*}{ 6FDA-6FpDA } & Permeance, $10^{2}\left(\mathrm{~m}_{\mathrm{STP}}{ }^{3} \mathrm{~m}^{-2} \mathrm{~h}^{-1} \mathrm{bar}^{-1}\right) *$ & 46.1 & 41.3 & 8.35 & 1.23 & 2.05 \\
\hline & Activation Energy $\left(E_{A}\right)\left(\mathrm{kJ} \mathrm{mol}^{-1}\right)$ & 5.58 & -3.45 & 3.08 & 8.95 & 6.51 \\
\hline & Selective layer thickness ${ }^{* *}(\mathrm{~nm})$ & 440 & 350 & 340 & 250 & 250 \\
\hline
\end{tabular}

${ }^{*} 1 \mathrm{~m}_{\mathrm{STP}}{ }^{3} \mathrm{~m}^{-2} \mathrm{~h}^{-1}$ bar $^{-1}=1.239 \times 10^{-10} \mathrm{~mol} \mathrm{~m}^{-2} \mathrm{~s}^{-1} \mathrm{~Pa}^{-1} ; 1000 \mathrm{GPU}=2.700 \mathrm{~m}_{\mathrm{STP}}{ }^{3} \mathrm{~m}^{-2} \mathrm{~h}^{-1} \mathrm{bar}^{-1}$. ${ }^{* *}$ The thickness of the selective layer estimated from gas transport data obtained for isotropic polymer film and TFCM.

The high-temperature gas transport measurement method was used for the evaluation of the permeance of the TFCMs with the selective layers of Matrimid ${ }^{\circledR}$ and 6FDA-6FpDA for the gases $\mathrm{H}_{2}$ and $\mathrm{CO}_{2}$. The pure gas permeance data were obtained for the two TFCMs in the temperature range $30-270{ }^{\circ} \mathrm{C}$ at 1 bar feed pressure and sweep gas flowrate $50 \mathrm{~mL} \mathrm{~min}^{-1}$. The permeance and selectivity values are presented in Table 3. It was possible to conduct reproducible gas transport measurements for the TFCMs up to $275^{\circ} \mathrm{C}$, which is in accordance with the TGA measurements (Figure 3). The temperature limit was imposed by the PPS non-woven support, as it started to melt at this point, causing the membrane to break. The $\mathrm{H}_{2} / \mathrm{CO}_{2}$ selectivity for Matrimid ${ }^{\circledR}$ was $\alpha_{\mathrm{H} 2 / \mathrm{CO} 2}=1.9$ and for 6FDA-6FpDA it was $\alpha_{\mathrm{H} 2 / \mathrm{CO} 2}=1.1$ at $30^{\circ} \mathrm{C}$, which are in good agreement with the data of pressure increase measurements. Since the activation energy for $\mathrm{CO}_{2}\left(E_{A, \mathrm{CO} 2}\right)$ is lower than $E_{A, \mathrm{H} 2}$, the $\mathrm{H}_{2} / \mathrm{CO}_{2}$ selectivities increased with the temperature for both membranes. For the 6FDA-6FpDA, a change in the $E_{A}$ values for $\mathrm{CO}_{2}$ was observed. The evolution of the permeance with the temperature for the gases $\mathrm{H}_{2}$ and $\mathrm{CO}_{2}$ is shown in Figure 6. In the case of Matrimid ${ }^{\circledR}$ (Figure 6a), a simple Arrhenius behavior was observed for both gases. Figure $6 \mathrm{~b}$ shows the evolution of the permeance with reciprocal temperature for the 6FDA-6FpDA. $\mathrm{H}_{2}$ permeance followed a simple Arrhenius behavior in the range from 30 to $270{ }^{\circ} \mathrm{C}$, while $\mathrm{CO}_{2}$ permeance exhibited a change in apparent $E_{A}$ values for temperatures above $170{ }^{\circ} \mathrm{C}$ for $\mathrm{CO}_{2}$. The absolute change of the gas permeance of $\mathrm{CO}_{2}$ in the $6 \mathrm{FDA}-6 \mathrm{FpDA}$ TFCM was very small, from $0.22 \mathrm{~m}_{\mathrm{STP}}{ }^{3} \mathrm{~m}^{-2} \mathrm{~h}^{-1} \mathrm{bar}^{-1}$ at $30^{\circ} \mathrm{C}$ to $0.19 \mathrm{mSTP}^{3} \mathrm{~m}^{-2} \mathrm{~h}^{-1} \mathrm{bar}^{-1}$ at $266{ }^{\circ} \mathrm{C}$, while the corresponding $E_{A}$ in a thick film of $6 \mathrm{FDA}-6 \mathrm{FpDA}$ (Table 1) was nearly $0 \mathrm{~kJ} \mathrm{~mol}^{-1}$. Therefore, further experiments will be done to analyze this observation. 
Table 3. Single gas separation properties and activation energies $\left(E_{A}\right)$ for the thin-film composite membranes in the range of temperatures between 30 and $266{ }^{\circ} \mathrm{C}$ for the gas pair $\mathrm{CO}_{2}$ and $\mathrm{H}_{2}$. The $E_{A}$ values were calculated between 30 and $266^{\circ} \mathrm{C}$.

\begin{tabular}{|c|c|c|c|c|c|c|}
\hline \multirow[b]{3}{*}{$T\left({ }^{\circ} \mathrm{C}\right)$} & \multicolumn{3}{|c|}{ Matrimid ${ }^{\circledR}$} & \multicolumn{3}{|c|}{ 6FDA-6FpDA } \\
\hline & \multicolumn{6}{|c|}{ Permeance, $10^{2}\left(\mathrm{~m}_{\mathrm{STP}}{ }^{3} \mathrm{~m}^{-2} \mathrm{~h}^{-1} \mathrm{bar}^{-1}\right)$} \\
\hline & $\mathbf{H}_{2}$ & $\mathrm{CO}_{2}$ & $\alpha_{\mathrm{H} 2 / \mathrm{CO} 2}$ & $\mathbf{H}_{2}$ & $\mathrm{CO}_{2}$ & $\alpha_{\mathrm{H} 2 / \mathrm{CO} 2}$ \\
\hline 30 & 3.86 & 2.05 & 1.88 & 24.2 & 22.0 & 1.10 \\
\hline 78 & 7.40 & 2.30 & 3.22 & 40.1 & 20.0 & 2.01 \\
\hline 125 & 12.0 & 2.62 & 4.58 & 56.5 & 16.6 & 3.40 \\
\hline 173 & 18.0 & 2.92 & 6.16 & 76.0 & 16.8 & 4.52 \\
\hline 202 & 21.4 & 3.09 & 6.92 & 89.6 & 17.3 & 5.18 \\
\hline 230 & 25.0 & 3.21 & 7.89 & 101 & 18.0 & 5.61 \\
\hline 248 & 27.5 & 3.24 & 8.49 & 107 & 18.4 & 5.82 \\
\hline 266 & 29.3 & 3.31 & 8.85 & 118 & 18.8 & 6.28 \\
\hline$E_{A}\left(\mathrm{~kJ} \mathrm{~mol}^{-1}\right)$ & 11.8 & 2.89 & - & 9.02 & $\begin{array}{l}-2.91\left(30-125^{\circ} \mathrm{C}\right) \\
2.45\left(173-266^{\circ} \mathrm{C}\right)\end{array}$ & - \\
\hline
\end{tabular}
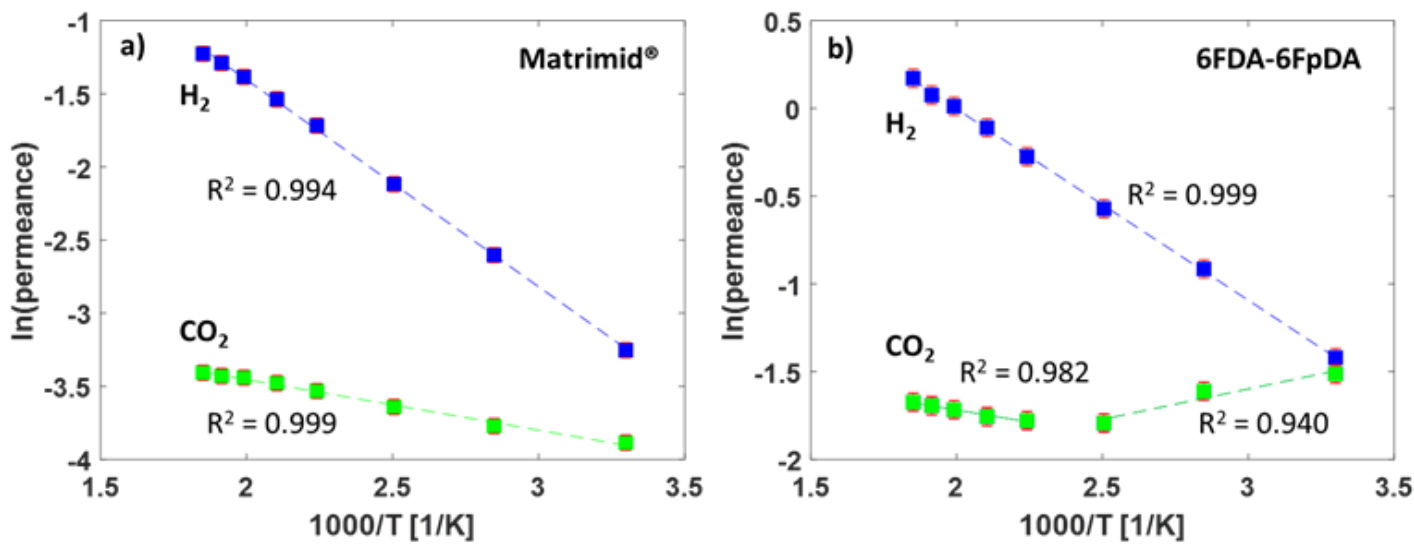

Figure 6. (a) Arrhenius plot for the TFCMs of Matrimid ${ }^{\circledR}$ and (b) 6FDA-6FpDA for temperatures between 30 and $266^{\circ} \mathrm{C}$.

In Figure 7 the selectivity of $\mathrm{H}_{2} / \mathrm{CO}_{2}$ over the temperature for the Matrimid ${ }^{\circledR}$ and the $6 \mathrm{FDA}-6 \mathrm{FpDA}$ TFCM are presented. With increasing temperature, $\mathrm{H}_{2} / \mathrm{CO}_{2}$ selectivity increased. The selectivity of the thick-film membranes was the highest in both polymers. Between 30 and $80{ }^{\circ} \mathrm{C}$, the selectivity followed the same trend for all membranes.
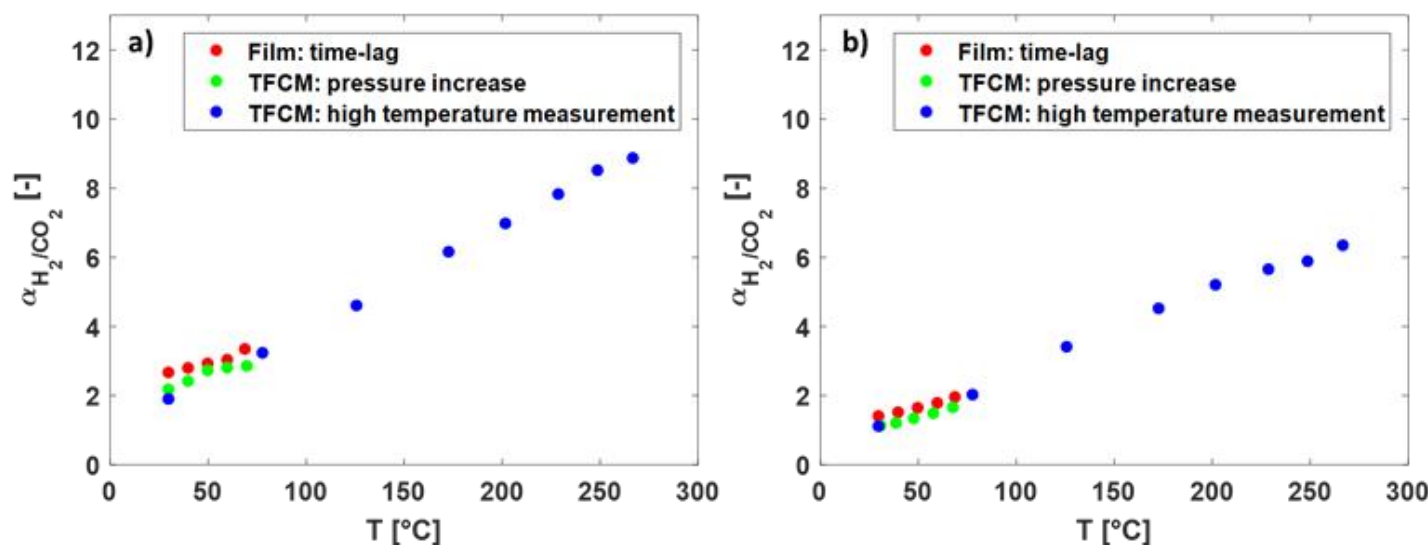

Figure 7. (a) The selectivity of $\mathrm{H}_{2} / \mathrm{CO}_{2}(-)$ over the temperature $\left({ }^{\circ} \mathrm{C}\right)$ in Matrimid ${ }^{\circledR}$ and (b) in 6FDA-6FpDA for different membranes and measurement methods. 


\section{Conclusions and Outlook}

A new highly thermally and chemically stable multilayer system for gas separation applications at elevated temperatures was introduced. The system was composed of four different layers: non-woven support, polyphenylene sulfide (PPS); polybenzimidazole (PBI) as polymeric porous support structure; two different polyimides-Matrimid ${ }^{\circledR}$ or 6FDA-6FpDA—as selective layers; and Teflon ${ }^{\circledR}$ AF 2400 as an external protective layer. The selective layers were successfully deposited as thin layers $(<1 \mu \mathrm{m})$ on top of the porous PBI support.

These thin-film composite membrane (TFCM) systems showed high thermal stability and promising results for the separation $\mathrm{H}_{2} / \mathrm{CO}_{2}$ at elevated temperatures. The separation properties of the materials characterized in different thicknesses and by several techniques were compared. This multilayer approach showed thermal stability for temperatures up to $270{ }^{\circ} \mathrm{C}$.

This type of highly thermally resistant polymeric membranes opens opportunities for application in integrated processes operated at elevated temperatures, such as membrane reactors for the water-gas shift reaction in order to maximize $\mathrm{H}_{2}$ yield.

Nevertheless, more efforts should be made toward the optimization of the thickness of the selective and protective layers; the stability of the non-woven support (which in this case was an important limitation); and new thermally resistant and highly selective polymers need to be tested under these conditions. Furthermore, the multicomponent permeation performance of this new type of TFCM needs to be further investigated.

Author Contributions: A.T., S.E. (Sonia Escolástico), S.S., J.M.S., and T.B. conceived of the idea; F.W., S.E. (Sara Escorihuela), and A.D. designed, performed, and/or evaluated the experiments; A.T., S.E. (Sonia Escolástico), S.S., J.M.S., and T.B. assisted in the evaluations of the experiments; F.W. and S.E. (Sara Escorihuela) wrote the paper, while all authors contributed to the scientific discussion, revision, and finalization of the manuscript.

Funding: This work was financially supported by the project "New reactor technologies for chemical and biochemical synthesis processes" ("Neue Reaktortechnologien für Chemische und Biochemische Syntheseverfahren", FKZ: LFF FV 43), funded by the City of Hamburg (Freie und Hansestadt Hamburg, Behörde für Wissenschaft, Forschung und Gleichstellung), Germany, the Spanish Government (SEV-2016-0683, SVP-2014-068356, Project ENE2014-57651-R and IJCI-2016-28330 grants), and Generalitat Valenciana (PROMETEO/2018/006 grant).

Acknowledgments: The authors thank Silvio Neumann for thermal analysis experiments, Clarissa Abetz and Anke-Lisa Höhme for the scanning electron microscopy experiments, and the microscopy service at Universitat Politècnica de València (UPV) for the FIB and FE-SEM images.

Conflicts of Interest: The authors declare no conflict of interest.

\section{References}

1. Baker, R.W.; Staff, U.B. Membrane technology. In Kirk-Othmer Encyclopedia of Chemical Technology; J. Wiley \& Sons: New York, NY, USA, 2000.

2. Ladewig, B.; Al-Shaeli, M.N.Z. Fundamentals of Membrane Processes. In Fundamentals of Membrane Bioreactors: Materials, Systems and Membrane Fouling; Springer: Singapore, 2017; pp. 13-37.

3. Ismail, A.F.; Khulbe, K.C.; Matsuura, T. Gas Separation Membranes; Springer: Singapore, 2015; Volume 7.

4. Amooghin, A.E.; Sanaeepur, H.; Pedram, M.Z.; Omidkhah, M.; Kargari, A. New advances in polymeric membranes for $\mathrm{CO}_{2}$ separation. In Polymer Science: Research Advances, Practical Applications and Educational Aspects; Formatex Research Center: Badajoz, Spain, 2016; pp. 354-368.

5. Schuldt, K.; Pohlmann, J.; Shishatskiy, S.; Brinkmann, T. Applicability of PolyActive ${ }^{\mathrm{TM}}$ Thin Film Composite Membranes for $\mathrm{CO}_{2}$ Separation from C2H4 Containing Multi-Component Gas Mixtures at Pressures up to 30 Bar. Membranes 2018, 8, 27. [CrossRef] [PubMed]

6. Brinkmann, T.; Lillepärg, J.; Notzke, H.; Pohlmann, J.; Shishatskiy, S.; Wind, J.; Wolff, T. Development of $\mathrm{CO}_{2}$ Selective Poly (Ethylene Oxide)-Based Membranes: From Laboratory to Pilot Plant Scale. Engineering 2017, 3 , 485-493. [CrossRef] 
7. Peter, J.; Peinemann, K.-V. Multilayer composite membranes for gas separation based on crosslinked PTMSP gutter layer and partially crosslinked Matrimid ${ }^{\circledR} 5218$ selective layer. J. Membr. Sci. 2009, 340, 62-72. [CrossRef]

8. Shishatskiy, S.; Nistor, C.; Popa, M.; Nunes, S.P.; Peinemann, K.V. Polyimide asymmetric membranes for hydrogen separation: Influence of formation conditions on gas transport properties. Adv. Eng. Mater. 2006, 8, 390-397. [CrossRef]

9. Bai, J.; Founda, A.E.; Matsuura, T.; Hazlett, J.D. A study on the preparation and performance of polydimethylsiloxane-coated polyetherimide membranes in pervaporation. J. Appl. Polym. Sci. 1993, 48, 999-1008. [CrossRef]

10. Grünauer, J.; Filiz, V.; Shishatskiy, S.; Abetz, C.; Abetz, V. Scalable application of thin film coating techniques for supported liquid membranes for gas separation made from ionic liquids. J. Membr. Sci. 2016, 518, 178-191. [CrossRef]

11. Escorihuela, S.; Tena, A.; Shishatskiy, S.; Escolástico, S.; Brinkmann, T.; Serra, J.; Abetz, V. Gas Separation Properties of Polyimide Thin Films on Ceramic Supports for High Temperature Applications. Membranes 2018, 8, 16. [CrossRef]

12. Lu, G.; Da Costa, J.D.; Duke, M.; Giessler, S.; Socolow, R.; Williams, R.H.; Kreutz, T. Inorganic membranes for hydrogen production and purification: A critical review and perspective. J. Colloid Interface Sci. 2007, 314, 589-603. [CrossRef] [PubMed]

13. David, O.C.; Gorri, D.; Urtiaga, A.; Ortiz, I. Mixed gas separation study for the hydrogen recovery from $\mathrm{H} 2 / \mathrm{CO} / \mathrm{N} 2 / \mathrm{CO} 2$ post combustion mixtures using a Matrimid membrane. J. Membr. Sci. 2011, 378, 359-368. [CrossRef]

14. Koros, W.J.; Fleming, G. Membrane-based gas separation. J. Membr. Sci. 1993, 83, 1-80. [CrossRef]

15. Liaw, D.-J.; Wang, K.L.; Huang, Y.C.; Lee, K.R.; Lai, J.Y.; Ha, C.S. Advanced polyimide materials: Syntheses, physical properties and applications. Prog. Polym. Sci. 2012, 37, 907-974. [CrossRef]

16. Weigelt, F.; Georgopanos, P.; Shishatskiy, S.; Filiz, V.; Brinkmann, T.; Abetz, V. Development and Characterization of Defect-Free Matrimid ${ }^{\circledR}$ Mixed-Matrix Membranes Containing Activated Carbon Particles for Gas Separation. Polymers 2018, 10, 51. [CrossRef]

17. Melin, T.; Rautenbach, R. Membranverfahren: Grundlagen der Modul-und Anlagenauslegung; Springer-Verlag: Berlin, Germany, 2007.

18. Barrer, R.; Rideal, E.K. Permeation, diffusion and solution of gases in organic polymers. Trans. Faraday Soc. 1939, 35, 628-643. [CrossRef]

19. Bains, P.; Psarras, P.; Wilcox, J. $\mathrm{CO}_{2}$ capture from the industry sector. Prog. Energy Combust. Sci. 2017, 63, 146-172. [CrossRef]

20. Malerød-Fjeld, H.; Clark, D.; Yuste-Tirados, I.; Zanón, R.; Catalán-Martinez, D.; Beeaff, D.; Morejudo, S.H.; Vestre, P.K.; Norby, T.; Haugsrud, R.; et al. Thermo-electrochemical production of compressed hydrogen from methane with near-zero energy loss. Nat. Energy 2017, 2, 923-931. [CrossRef]

21. Stolten, D.; Emonts, B. Hydrogen Science and Engineering, 2 Volume Set: Materials, Processes, Systems, and Technology; John Wiley \& Sons: Hoboken, NJ, USA, 2016; Volume 1.

22. Rezakazemi, M.; Sadrzadeh, M.; Matsuura, T. Thermally stable polymers for advanced high-performance gas separation membranes. Prog. Energy Combust. Sci. 2018, 66, 1-41. [CrossRef]

23. Pesiri, D.R.; Jorgensen, B.; Dye, R.C. Thermal optimization of polybenzimidazole meniscus membranes for the separation of hydrogen, methane, and carbon dioxide. J. Membr. Sci. 2003, 218, 11-18. [CrossRef]

24. Kumbharkar, S.C.; Liu, Y.; Li, K. High performance polybenzimidazole based asymmetric hollow fibre membranes for H2/CO2 separation. J. Membr. Sci. 2011, 375, 231-240. [CrossRef]

25. Berchtold, K.A.; Singh, R.P.; Young, J.S.; Dudeck, K.W. Polybenzimidazole composite membranes for high temperature synthesis gas separations. J. Membr. Sci. 2012, 415, 265-270. [CrossRef]

26. Costello, L.M.; Koros, W.J. Thermally stable polyimide isomers for membrane-based gas separations at elevated temperatures. J. Polym. Sci. Part B 1995, 33, 135-146. [CrossRef]

27. Muñoz, D.M.; de La Campa, J.G.; de Abajo, J.; Lozano, A.E. Experimental and theoretical study of an improved activated polycondensation method for aromatic polyimides. Macromolecules 2007, 40, 8225-8232. [CrossRef]

28. Herdegen, V.; Werner, A.; Milew, K.; Haseneder, R.; Aubel, T. ACHEMA 2018: Membranes and Membrane Separation. Chem. Ing. Tech. 2018, 90, 1964-1971. [CrossRef] 
29. Wang, K.Y.; Chung, T.-S. Fabrication of polybenzimidazole (PBI) nanofiltration hollow fiber membranes for removal of chromate. J. Membr. Sci. 2006, 281, 307-315. [CrossRef]

30. Ansaloni, L.; Minelli, M.; Baschetti, M.G.; Sarti, G.C. Effects of thermal treatment and physical aging on the gas transport properties in Matrimid ${ }^{\circledR}$. Oil Gas Sci. Technol. 2015, 70, 367-379. [CrossRef]

31. Pye, D.; Hoehn, H.; Panar, M. Measurement of gas permeability of polymers. I. Permeabilities in constant volume/variable pressure apparatus. J. Appl. Polym. Sci. 1976, 20, 1921-1931. [CrossRef]

32. Tena, A.; Shishatskiy, S.; Meis, D.; Wind, J.; Filiz, V.; Abetz, V. Influence of the composition and imidization route on the chain packing and gas separation properties of fluorinated copolyimides. Macromolecules 2017, 50, 5839-5849. [CrossRef]

(C) 2019 by the authors. Licensee MDPI, Basel, Switzerland. This article is an open access article distributed under the terms and conditions of the Creative Commons Attribution (CC BY) license (http://creativecommons.org/licenses/by/4.0/). 